\title{
Risk tolerance, investment horizons and debt decisions
}

\author{
$\underline{\text { Trang Phung }}{ }^{\mathrm{a}}$, Wendy Hsu ${ }^{\mathrm{b}}$, Michael Naylor ${ }^{\mathrm{c}}$ and Martin Young ${ }^{\mathrm{d}}$ \\ ${ }^{a, b, c, d}$ School of Economics and Finance, Massey University, New Zealand.
}

Email:T.Phung@massey.ac.nz

\begin{abstract}
Formal and informal debt play an important role in investors' choices. The literature on investors' use of debt is, however, limited. In particular, the impact of risk tolerance and investment horizons on debt decisions has been unexplored.

Vietnam is uniquely useful as informal borrowing is common in Vietnamese culture. Using data of 420 individual investors, we find a direct impact of (i) risk tolerance and short horizons on financial leverage, (ii) preference for short-term over long-term stock investment (SHOLO) on investment risk tolerance and informal debt, and (iii) long horizons on informal debt. SHOLO indirectly linked investment risk tolerance and informal debt. Investment risk tolerance linked SHOLO to financial leverage. These results are robust after controlling for demographics and using additional techniques.

The implications are that individual investors should consider the degree of risk tolerance when making decisions on investment horizons and borrowings because the higher the levels of risk tolerance, the higher is the preference for a short trading horizon, and the higher the preference for financial leverage. Both the preference for short-term over long-term stock investment and long horizons cause risk-tolerant investors to use high informal debt. Additionally, investors' attention needs to be drawn to the fact that if their stock investment fails, all lenders may be severely affected.
\end{abstract}

Keywords: Debt decisions, financial leverage, informal debt, investment horizons, long-term investment 


\section{INTRODUCTION}

Risk tolerance lies at the heart of the financial field because it affects a broad range of personal financial choices (Grable \& Lytton, 2001). Risk tolerance, sometimes known as risk preference, has originated from behavioural finance theory and defined as the attitude towards taking financial risks. As stated by Grable and Lytton (2001), risk tolerance encompasses three categories: investment risk, financial risk, and speculative risk and has three levels: low, moderate, and high; high-risk tolerance is represented with a convex utility function and low-risk tolerance with a concave utility function.

Investment horizons refer to the length of time (e.g. weekly, monthly, quarterly, or annually) that an investor holds an asset or a portfolio (Levhari \& Levy, 1977). The underlying assumption of capital asset pricing (CAPM) that all investors make decisions based on their maximum expected utility regardless of the length of the investment period, has often been criticized. For example, Levhari and Levy (1977) claim that the assumed investment horizons strongly influence estimates of the systematic risk of securities and their performance whereby an increase in the investment horizons leads to a decrease in the systematic risk of defensive stocks and a rise in the systematic risk of aggressive stocks. Leibowitz and Langetieg (1989) stated that the differences in investment horizon cause inverse outcomes between risky (e.g. stocks) and safe (e.g. bonds) investment.

Recent literature on informal and formal debt has paid much attention to households, e.g. (Nguyen \& Berg, 2014), but little attention to individual investors. Also, the bulk of literature focuses on the relationship between risk tolerance and investment decisions (Dorn \& Huberman, 2005; Grable \& Lytton, 2001), but no research highlights the link between risk tolerance, stock investment horizons, and debt decisions. This paper aims to start to close this gap.

We characterise debt decisions as the debt levels investors use for their stock investment, including two measures: informal debt and financial leverage. (i) Informal debt is viewed as the amount investors borrow from informal lenders, and appears common in developing countries, e.g. Vietnam (Nguyen \& Berg, 2014). Informal lenders are families, relatives, friends, landlords, or moneylenders (Nguyen \& Berg, 2014). (ii) Financial leverage is described as the credit investors obtain through brokerage firms. Financial leverage is seen as the lending ratios published by brokerage firms. Under the securities law, the maximum lending ratio is 1:1, meaning that for each dollar equity, an investor could borrow one more dollar.

We conducted our study in Vietnam due to its unique use of informal debt. The majority of Vietnamese are in the range of working age. The Vietnam stock market, founded in 2000, has increasingly developed and has been one of the fastest-growing emerging stock markets in Asia. Usefully, individual investors dominate the stock market, making up 99 per cent of total participants. This feature differs from the developed stock markets, where institutional investors predominate. Based on these features, we expect Vietnamese investors to provide a uniquely useful insight into the attitudes of investors in emerging stock markets affecting their investment choices.

\section{LITERATURE REVIEW AND HYPOTHESIS DEVELOPMENT}

Risk tolerance is positively associated with risky choices; for example, investors with high risk-tolerance levels choose higher-risk portfolios (Corter \& Chen, 2006). Highly risk-tolerant investors hold less diversified portfolios and trade more aggressively (Dorn \& Huberman, 2005). The higher the risk tolerance, the higher the proportion of funds invested in stocks rather than bonds (Bailey \& Kinerson, 2005).

Hodges, Taylor, and Yoder (1997) find that the average returns and risk of the small stocks, common stocks, and bonds tend to increase with the length of the holding periods. For example, profits of the small stocks increase by 17 per cent for a 1-year holding period in response to an increase in the risk of these stocks by 34 per cent. Remarkably, the average returns of the small stocks rise to six years and then decrease steadily, and the average returns of the common stocks increase to 11 years and then decline while the average returns of bonds go up over a 30-year holding period. Bebchuk and Stole (1993) thus find that short-term objectives and imperfect information result in over-investment in the long-term projects. As a result, it appears that no research addresses the direct relationship between risk tolerance, investment horizons, and debt decisions. Based on the 
results of Levhari and Levy (1977) in which the longer the holding period is, the lower the risk of defensive stocks and the higher the risk of aggressive stocks. Given this evidence, the following hypothesises are:

H1-H2: The higher the levels of risk tolerance, the more the choice for short over long horizons (H1) and the higher the levels of financial leverage used (H2).

H3: The more the preference for short over long horizons, the higher the levels of risk tolerance.

H4: The more the preference for short horizons, the higher the levels of financial leverage used.

H5-H6: The more the preference for long horizons (H5) and the higher the preference for short over long horizons (H6), the higher the levels of informal debt used.

Several prior researchers find that perceived risk (performance risk) acts as a link between perceived quality and value (Sweeney, Soutar, \& Johnson, 1999), and that financial risk serves as a link between perceived sacrifice and perceived value (Agarwal \& Teas, 2001). Perceived uncertainty links extraversion to investment decisions (Phung \& Mai, 2017). There is no research on the mediating roles of risk tolerance and investment horizons. Based on the evidence of the impact of investment horizons on systematic risk (Levhari \& Levy, 1977) and risk tolerance on risky decisions (Corter \& Chen, 2006), we established the following two additional hypotheses:

H7: Risk tolerance indirectly affects informal debt through the preference for short over long horizons.

H8: Preference for short over long horizons indirectly influences financial leverage through risk tolerance.

\subsection{Methods applied to test casual relationships}

Our sample size of 420 observation conforms with the guideline by (Hair, Black, Babin, \& Anderson, 2014). Measures of three main factors in the model are as follows: (i) Risk tolerance (RITO): the scores of risk tolerance are computed based on the 13-item scale (Grable \& Lytton, 1999). Risk tolerance comprises three facets: investment risk (INVRT), financial risk (FINRT) and speculative risk (SPERT). This 13-item scale is used by many scholars and assessed as a high explanatory instrument (Gilliam, Chatterjee, \& Grable, 2010). (ii) Investment horizons: Based on prior researchers, e.g. Vives (1995), investment horizons have three measures: short-term (less than one year) (SHOR), long-term (one year or more) (LONG), and short term over long term investment stocks (SHOLO). (iii) Debt decisions include informal debt (INFD) and financial leverage (LEVE).

\section{RESULTS}

Investor characteristics are summarized as follows: male investors dominated the sample, making up around $61 \%$. Most investors were in the range of working age of 25-35 (57\%). Most of them were single (about $61 \%$ ), had a university degree (about $86 \%$ ), earned income between 10 and 50 million VND per month (equivalent to 500 and 2500 USD per month) (around 53\%), had financial literacy above the average (59\%), and had five years or less of stocks investment (about 78\%).

We developed three structural equation models (SEMs), whereby SEM1 and SEM2 examined the direct role of risk tolerance and the mediating role of investment horizons. SEM 3 tested the direct role of investment horizons and the mediating role of risk tolerance. We found significant relationships between factors in Figures 1,2 , and 3 with standardized estimates. These results are robust using additional techniques such as multiple regression, stepwise, and the approach of Hayes and Preacher (Hayes \& Preacher, 2010).

Figure 1 (SEM1) indicated a direct impact of risk tolerance (RITO) on financial leverage (LEVE) by the standardized coefficient of $0.13(p<0.05)$, and of short-term over long-term investment (SHOLO) on informal debt (INFD) by $0.1(p<0.05)$. Figure 2 (SEM2) discovered the effects of investment risk tolerance (INVRT) on SHOLO by $0.12(p<0.05)$ and SHOLO on INFD at $0.1(p<0.05)$, meaning that SHOLO mediated between INVRT and INFD by $0.012(p<0.05)$. Moreover, financial risk tolerance (FINRT) and speculative risk tolerance (SPERT) influenced LEVE by $0.17(p<0.05)$ and $-0.11(p<0.05)$, respectively. Figure 3 (SEM3) revealed the influences of SHOLO on INVRT by $0.12(p<0.05)$, and INVRT on LEVE by $0.1(p<0.05)$, that is, INVRT mediated between SHOLO and LEVE by $0.012(p<0.05)$. SEM3 also explored the impact of short- 
term stock investment (SHOR) on LEVE by $0.14(p<0.01)$, and SHOLO and LONG on INFD by $0.14(p<0.01)$ and $0.09(p<0.1)$, respectively. In demographics, as shown in Figures 1, 2, and 3, there was an impact of EDU on SHOLO, MAR on INFD, INC and FIL on LEVE at a significant level $(p<0.05)$, respectively.

\section{ROBUSTNESS CHECK}

We employed multiple and stepwise regression to retest the direct relationships, and Hayes and Preacher to retest the indirect relationships found by SEMs. It is noted that all models with multiple and stepwise regression techniques were tested after controlling for variables of gender, age, marital status, education, income and financial literacy.

As indicated in Table 1, for the direct relationships, most results with multiple and stepwise regression were consistent with those found by SEMs, except the association between SPERT and LEVE in the stepwise technique. For the indirect relationships, Hayes and Preacher's approach found INVRT mediated between SHOLO and LEVE at a significant level $(p<0.1)$, being similar to SEM3' results. Hayes and Preacher's approach, however, found an insignificant mediating role of SHOLO in the relationship between INVRT and INFD, being inconsistent with SEM2' findings. Some inconsistencies are perhaps due to different methods. SEM tests the covariances between variables and indirect relationships between multiple independent and dependent variables in a model, while multiple regression, stepwise, and Hayes and Preacher's approach cannot test the covariances between variables and examines a causal relationship with only one dependent variable.

Table 1. The results of multiple regression, stepwise, and Hayes and Preacher

\begin{tabular}{|c|c|c|c|c|c|c|}
\hline Direct and indirect impact & SEMs & $\begin{array}{l}\text { Multiple } \\
\text { regression }\end{array}$ & $\begin{array}{l}\text { Stepwise } \\
\text { regression }\end{array}$ & $\begin{array}{l}\text { Hayes \& } \\
\text { Preacher }\end{array}$ & SEMs & $\begin{array}{c}\text { Hypothesis } \\
\text { supported }\end{array}$ \\
\hline \multicolumn{7}{|l|}{ I/ Direct impact } \\
\hline 1. SHOLO->INFD & $0.097 * *$ & $0.097 *$ & $0.095 * *$ & & SEM1 & H6 \\
\hline 2. RITO->LEVE & $0.127 * * *$ & $0.133 * * *$ & $0.139 * * *$ & & SEM1 & $\mathrm{H} 2$ \\
\hline 3. INVRT->SHOLO & $0.124 * *$ & $0.110 * *$ & $0.109 * *$ & & SEM2 & H1 \\
\hline 4. SHOLO->INFD & $0.1 * *$ & $0.097 *$ & $0.095 * *$ & & SEM2 & H6 \\
\hline 5. SPERT->LEVE & $-0.11 * *$ & -0.24 & Not found & & SEM2 & $\mathrm{H} 2$ \\
\hline 6. FINRT->LEVE & $0.173 * * *$ & $0.164 * * *$ & $0.170 * * *$ & & SEM2 & $\mathrm{H} 2$ \\
\hline 7. SHOLO->INVRT & $0.121 * *$ & $0.110^{* *}$ & $0.105 * *$ & & SEM3 & $\mathrm{H} 3$ \\
\hline 8. LONG->INFD & $0.089 *$ & $0.097 * *$ & $0.095 * *$ & & SEM3 & H5 \\
\hline 9. SHOR-> LEVE & $0.139 * * *$ & $0.145^{* * *}$ & $0.138 * * *$ & & SEM3 & $\mathrm{H} 4$ \\
\hline 10. INVRT->LEVE & $0.102 * *$ & $0.104 * *$ & $0.106 * *$ & & SEM3 & $\mathrm{H} 2$ \\
\hline 11. SHOLO->INFD & $0.142 * * *$ & $0.097^{*}$ & $0.095 * *$ & & SEM3 & H6 \\
\hline \multicolumn{7}{|l|}{ II/ Indirect impact } \\
\hline 12. INVRT->SHOLO-> INFD & $0.012 * *$ & & & 0.0011 & SEM2 & $\mathrm{H} 7$ \\
\hline 13. SHOLO-> INVRT-> LEVE & $0.012 * *$ & & & $0.0045 *$ & SEM3 & $\mathrm{H} 8$ \\
\hline
\end{tabular}

\section{DISCUSSIONS}

We found that investors obtained credit through, ranked in descending order, (i) family: parents, grandparents, other family sources (e.g. aunts or uncles), husband/wife, parents-in-law, brothers or sisters (in-law); (ii) nonfamily: friends, other non-family sources, colleagues/co-workers, girlfriend/boyfriend/partner, business partners, neighbours, and bosses/managers; (iii) brokerage firms, banks, credit institutions, and other sources. Primary lenders are parents, friends, and brokerage firms, and a total money portfolio for stock investment composed $18 \%$ of the informal debt, $21 \%$ of the formal debt, and $61 \%$ of own money on average.

Our findings supported the hypotheses. In the direct role, we found the impact of risk tolerance (investment risk tolerance) on the preference for short-term over long-term stock investment (SHOLO) in support of H1. We also found the impact of risk tolerance, investment, financial and speculative risk tolerance on financial leverage (H2), SHOLO on investment risk tolerance (H3), short horizons on financial leverage (H4), long horizons on informal debt (H5), and SHOLO on informal debt (H6). In indirect roles, we documented that 


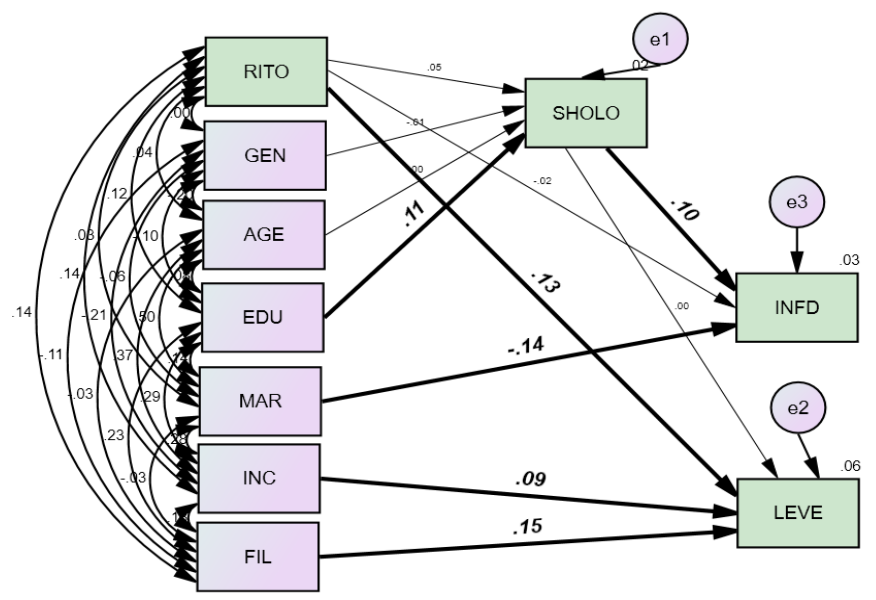

Figure 1. Risk tolerance, investment horizons, and debt decisions (SEM1) Model fit: Chi-square: 9.631, df: 13, GFI: 1.000, TLI: 1.037, CFI: 1.000, RMSEA: 0.000.

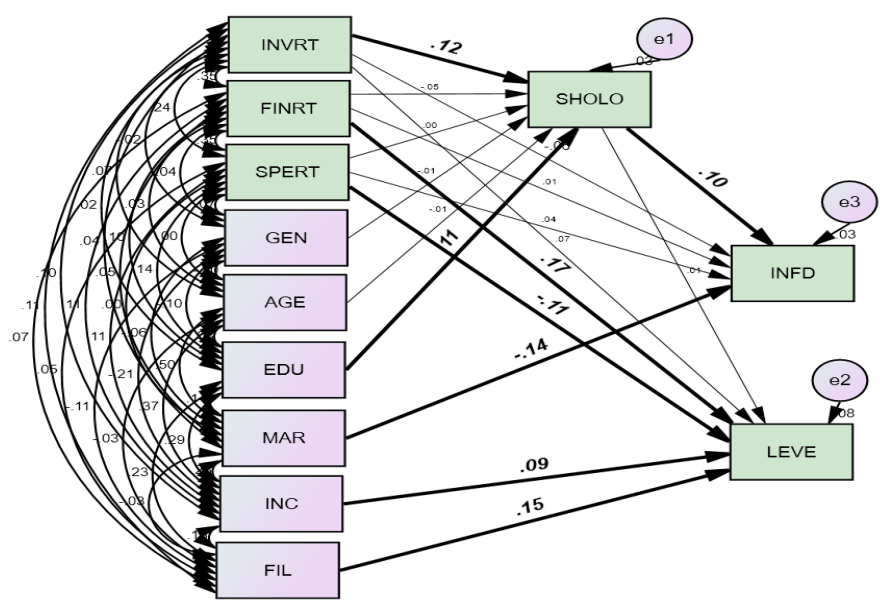

Figure 2. Three facets of risk tolerances, investment horizons, and debt decisions (SEM2) Model fit: Chi-square: 7.903, df: 13, GFI: 0.997, TLI: 1.060, CFI: 1.000, RMSEA: 0.000.

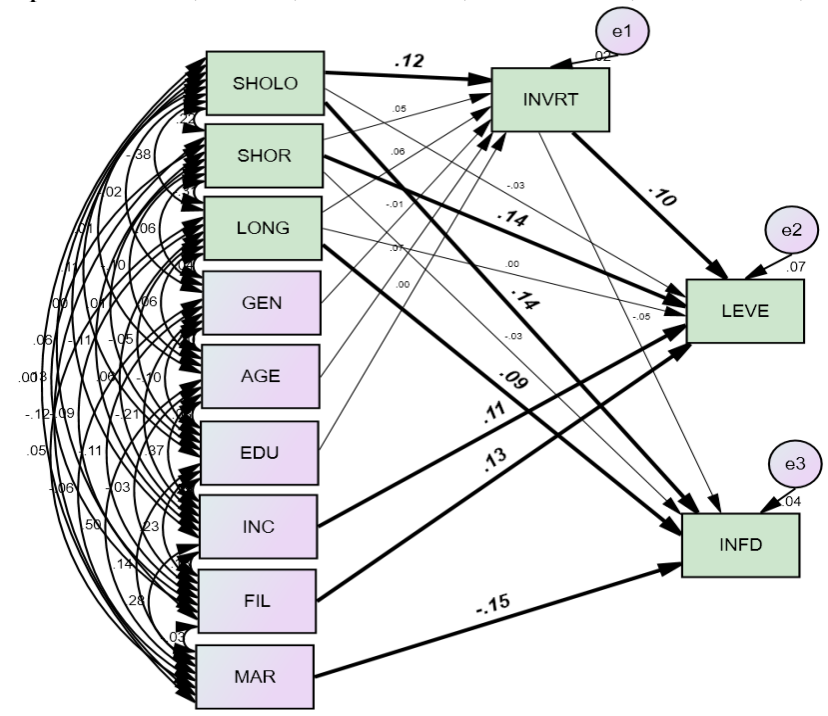

Figure 3. Investment horizons, investment risk tolerance, and debt decisions (SEM3) Model criteria: Chi-square: 14.233, df: 13, GFI: 0.994, TLI: 0.986, CFI: 0.997, RMSEA: 0.015. ${ }^{1}$

\footnotetext{
${ }^{1}$ Note: RITO: risk tolerance, INVRT: investment risk tolerance, FINRT: financial risk tolerance, SPERT: speculative risk tolerance, GEN: gender, AGE: age, MAR: marital status, INC: income, EDU: education levels, FIL: financial literacy, SHOLO: short-term over long-term stock investment, SHOR: short-term stock investment, LONG: long-term stock investment, INFD: informal debt, LEVE: financial leverage. ${ }^{*}$ : $<<0.1, * *: \mathrm{p}<0.05, * * * \mathrm{p}<0.01$.
} 
SHOLO mediated between investment risk tolerance and informal debt $(\mathrm{H} 7)$, and investment risk tolerance linked SHOLO to financial leverage (H8). The following discussions are:

(i) Debt decisions are measured by informal debt and financial leverage. For informal debt, approximately 45 per cent of investors had no informal debt, that is, 55 per cent of them used informal debt, between $5 \%$ and $100 \%$, to invest in stocks. Of those, the majority used informal debt in the range between around $10 \%$ and $50 \%$. Approximately 78 per cent of investors used financial leverage for their stock investment (around 20 per cent did not use leverage, and two per cent did not answer this question), and the ratios between $30 \%$ to the maximum leverage dominate.

(ii) In investment horizons, the average investment horizon was divided into 60 per cent for short horizons (less than one year) and 40 per cent for long horizons (one year or more). Only 3.3 per cent of investors did not invest in stocks for short horizons, meaning that most investors (about 97\%) preferred investing in stocks for less than one year. Of these, stock investment with less than six months made up 77 per cent. Nearly 80 per cent of investors had a long-term stock investment. Investment horizons also exerted positive influences on risk tolerance, financial leverage and informal debt. That is the levels of financial leverage or informal debt increase with an increase in short and long term stock investment. Remarkably, short termists (those who invest in stocks for less than one year) tend to use higher financial leverage, and long termists (those who invest in stocks for one year or more) are likely to use higher informal debt. Also, short-over-long termists (those who invest in more short-term stocks than long-term stocks) tend to use higher informal debt. These findings appear consistent with those of prior studies (Hodges et al., 1997; Levhari \& Levy, 1977). We found no direct impact of SHOLO on financial leverage but found its indirect influence on financial leverage through investment risk tolerance. That is, investment risk tolerance causes short-over-long termists to use higher financial leverage.

(iii) In the levels of risk tolerance, according to Grable and Lytton (2001), if decision-makers' scores of risk tolerance are more than (equal to or less than) the average, they had high (moderate or low) levels of risk tolerance, that is, they are highly (moderately or less) willing to take on risk. Our data displayed that 49 per cent of investors had the scores less than the average (mean: 29.4), meaning that they had low levels of risk tolerance (i.e. less willingness to take on risk). Over half of the respondents (51\%) had the scores higher than mean, exhibiting they had high levels of risk tolerance. Likewise, investors had higher scores of tolerance of investment risk (62\%), financial risk (51\%), and speculative risk (57\%) than the average. Overall, investors with a high willingness to take on risk dominate the sample. Risk tolerance overall had a positive relationship with the preference for short-term over long-term stock investment (SHOLO), financial leverage, and informal debt, meaning that the higher the levels of risk tolerance, the more the preference for short-term over long-term stock investment, and the higher the levels of financial leverage and informal debt. These results are in line with prior research on the higher the levels of risk tolerance the riskier the decisions are made (Grable \& Lytton, 2001). It is noted that we found no direct impact of risk tolerance on informal debt but found an indirect effect on informal debt through SHOLO. This indicates that the preference for short over long horizons cause risktolerant investors to use high informal debt.

\section{CONCLUSIONS, IMPLICATION, AND FURTHER RESEARCH}

Our empirical study provided the portrait of individual investors' use of debt, including financial leverage and informal debt and completed our research objective. We found the direct impact of (i) risk tolerance and short horizons on financial leverage, (ii) preference for short-term over long-term stock investment (SHOLO) on investment risk tolerance and informal debt, and (iii) long horizons on informal debt. For the indirect impact, (iv) SHOLO mediated between investment risk tolerance and informal debt. (v) Investment risk tolerance linked SHOLO to financial leverage. These findings are robust after controlling for demographic variables and using alternative methods. Our study is beneficial to the following subjects. For academic researchers, our contributions are to develop the structural equation models with direct and indirect relationships between risk tolerance, investment horizons, and debt decisions and to uncover these relationships at a significant level. For investors (stockbrokers and non-stockbrokers): investors should pay much attention to the levels of risk tolerance because an increase in levels of risk tolerance leads to a rise in the use of financial leverage and informal debt. More importantly, risk tolerance causes short-over-long termists to use higher levels of financial 
leverage. Also, the preference for short-term over long-term stock investment leads risk-tolerant investors to use higher informal debt. These results draw attention to investors that if their stock investment fails, all lenders may be severely affected. Our results also assist bankers, brokerage firms, and policymakers in a better understanding of the fact of the use of informal and formal debt by investors.

We also suggest having further research on investors' use of debt since this theme has yet been of much interest to researchers. Moreover, we find informal lenders are one of the primary lenders of investors but have yet shed light on some issues in terms of informal debt. The following open questions are (i) do investors pay loan interest to informal lenders? (ii) do investors and informal lenders share profit or loss based on their contributed capital? (iii) do informal lenders use their own money to lend to investors? (iv) apart from risk tolerance, does risk perception or trust affect their debt decisions? We leave these questions to further studies.

\section{REFERENCES}

Agarwal, S., \& Teas, R. K. (2001). Perceived value: mediating role of perceived risk. Journal of Marketing theory and Practice, 9(4), 1-14.

Bailey, J. J., \& Kinerson, C. (2005). Regret avoidance and risk tolerance. Journal of Financial Counseling and Planning, 16(1), 23-28.

Bebchuk, L. A., \& Stole, L. A. (1993). Do short-term objectives lead to under-or overinvestment in long-term projects? The journal of Finance, 48(2), 719-729.

Corter, J. E., \& Chen, Y.-J. (2006). Do investment risk tolerance attitudes predict portfolio risk? Journal of Business and Psychology, 20(3), 369-381.

Dorn, D., \& Huberman, G. (2005). Talk and action: What individual investors say and what they do. Review of Finance, 9(4), 437-481. doi:https://doi.org/10.1007/s10679-005-4997-Z

Gilliam, J., Chatterjee, S., \& Grable, J. E. (2010). Measuring the perception of financial risk tolerance: A tale of two measures. Journal of Financial Counseling and Planning, 21(2), 30-43.

Grable, J. E., \& Lytton, R. H. (1999). Financial risk tolerance revisited: the development of a risk assessment instrument污. Financial Services Review, 8(3), 163-181.

Grable, J. E., \& Lytton, R. H. (2001). Assessing the concurrent validity of the SCF risk tolerance question. Journal of Financial Counseling and Planning, 12(2), 43-53.

Hair, J., Black, W., Babin, B. J., \& Anderson, R. (2014). Multivariate Data Analysis, 7th Edition: Harlow, UK: Pearson Education Limited.

Hayes, A. F., \& Preacher, K. J. (2010). Quantifying and testing indirect effects in simple mediation models when the constituent paths are nonlinear. Multivariate behavioral research, 45(4), 627-660.

Hodges, C. W., Taylor, W. R., \& Yoder, J. A. (1997). Stocks, bonds, the Sharpe ratio, and the investment horizon. Financial Analysts Journal, 53(6), 74-80.

Leibowitz, M. L., \& Langetieg, T. C. (1989). Shortfall Risk And The Asset Allocation Decision: A Simulat. Journal of Portfolio Management, 16(1), 61-68.

Levhari, D., \& Levy, H. (1977). The capital asset pricing model and the investment horizon. The Review of Economics and Statistics, 92-104. doi:https://www.jstor.org/stable/1924908

Nguyen, V. C., \& Berg, v. d. M. (2014). Informal Credit, Usury, or Support? A Case Study for Vietnam. The Developing Economies, 52(2), 154-178.

Phung, T. M. T., \& Mai, N. K. (2017). Personality Traits, Perceived Risk, Uncertainty, and Investment Performance in Vietnam. Global Business and Finance Review, 22, 67-79.

Sweeney, J. C., Soutar, G. N., \& Johnson, L. W. (1999). The role of perceived risk in the quality-value relationship: a study in a retail environment. Journal of retailing, 75(1), 77-105.

Vives, X. (1995). Short-term investment and the informational efficiency of the market. The Review of Financial Studies, 8(1), 125-160. doi:https://doi.org/10.1093/rfs/8.1.125 